\title{
National map contest for cartographic education
}

\author{
Takuma UDA $^{\mathrm{a},}$, Takaki OKATANI ${ }^{\mathrm{b}}$ \\ ${ }^{a}$ Geospatial Information Authority of Japan; uda-t96mw@mlit.go.jp \\ ${ }^{b}$ Geospatial Information Authority of Japan; okatani-t96ms@mlit.go.jp \\ * Corresponding author
}

Keywords: National Map Contest for Pupils and Students, Local Map Contest, Cartographic Education

\begin{abstract}
:
In Japan, many local map contests are held in various places. Among those contests, 14 organizations are involved in the council of national map contest for pupils and students with some public interest corporations. The Geospatial Information Authority of Japan (GSI) plays a role as the secretariat of the council. In 2019, the $22^{\text {nd }}$ contest was held and 2 applicants received Ministers' Awards, one by the Minister of Land, Infrastructure, Transport and Tourism, and the other by the Minister of Education, Culture, Sports, Science and Technology. The contest has been playing an important role for encouraging pupils and students to be familiar with cartography.
\end{abstract}

\section{Introduction}

In Japan, many local map contests are held in various places. Among those contests, 14 organizations are involved in the council of national map contest for pupils and students. These local map contests are held in Sapporo, Asahikawa*, Sendai, Ibaraki, Tama, Toyama, Gifu, Kyoto*, Kobe, Ako, Tottori, Hiroshima, Tokushima, and Oita. In addition to these organizations, 3 public interest corporations also take part in the council, namely Japan Map Center, Mapping Technology Association, and "Chizu-kyokai" (map association). Geospatial Information Authority of Japan (GSI) plays a role as the secretariat of the council.

*: Although the secretariats of these contests are located in the above cities, applicants are not limited to the local areas; Asahikawa's contest is worldwide and Kyoto's contest in nationwide.

\section{The National Map Contest for Pupils and Students}

Like the worldwide Barbara Petchenik Children's Map Competition, Japan has the national map contest for pupils and students. Its $22^{\text {nd }}$ contest was held in January 2019, and the ministers' awards went to 2 applicants, one by Minister of Land, Infrastructure, Transport and Tourism, and the other by the Minister of Education, Culture, Sports, Science and Technology. Many of awarded maps in the previous contests were often focused on research for environment, security, disaster prevention and other themes. In addition, precise 3D topographic models were often awarded. Usually, around 100 maps are nominated to the annual contests, and the Director-General of GSI's Award and the Chair's Award are also sent to applicants in addition to Ministers' Awards.

While the national contest has been held for more than 20 years, there are some local contest with much longer history; Hiroshima's is for 57 and Sendai's is for 50 years. We may say that these continued efforts have contributed much for promotion of cartographic education.

\section{Conclusions}

GSI supports the nationwide contest as the secretariat of the council for many years and the contest has contributed to promoting cartographic education for a long time. The author looks forward to discussing on the role of the National Map Contest in the promotion of cartographic education. 